\title{
Exploring E Turkey: Rainfall Precursor Predicts 100\% Earthquake in a Consistent Manner in Just 2 Weeks
}

\author{
Prakash Pillai \\ SQS Institute of NDT, Super Quality Services, Tiruchi, Tamilnadu, India \\ Email: apaprakash@yahoo.co.in
}

Received March 4, 2013; revised April 7, 2013; accepted May 5, 2013

Copyright (C) 2013 Prakash Pillai. This is an open access article distributed under the Creative Commons Attribution License, which permits unrestricted use, distribution, and reproduction in any medium, provided the original work is properly cited.

\begin{abstract}
Rainfall event is the very specific, reliable unambiguous precursor for the earthquake event. Over the years scientists have hunted for some signal—a precursory sign, however faint — that would allow forecasters to pin-point exactly where and when the big ones will hit. After decades spent searching in vain, many seismologists now doubt whether such a signal even exists. But in a great surprise to everyone, from an ordinary lay man to eminent scientists, $100 \%$ earthquakes occur after rainfalls! Though I have the findings for the entire regions of the world, here E Turkey are the region for submission for the period Jan-November, 2012 to study the strong correlation and show the strong evidence to prove that the $100 \%$ earthquakes after rainfall in a consistence manner. Anyone can very easily verify the validity of the findings for any forthcoming earthquakes for any regions of $E$ Turkey in just two weeks of period. Nature does not give two different results for the same phenomena, for two different observers. Though there exists a very strong relation between the rainfalls and the earthquakes, scientists and seismologists have not been able to detect and identify this rainfall precursory signal for hundreds of years that consistently occurs before earthquakes. The methodology of rainfall event before earthquakes, even works consistently for earthquake prediction purpose, especially in any regions of the world. Rainfall type precursor is the best approach to predict specific earthquakes, which provide the potential for estimating the epicenter and magnitude of any moderate to strong earthquakes. Earthquakes are more likely when there is rain than it is not. The magnitudes of a resulting individual earthquake depend on the severity of the weather changes. However, in a very few cases the time scales and magnitude do vary substantially as a consequence of local site geology and other factors.
\end{abstract}

Keywords: Earthquake Prediction; Earthquake Precursor; Rainfall Predicts Earthquakes; Weather Predicts Earthquakes

\section{Introduction}

The purpose of this paper is to identify the best earthquake precursor that can be predict of any individual earthquake(s) location and magnitude accurately in shortterm, that work really quite well than chance-correlation between the specific regional rain fall and to the respecttive individual regional earthquake in E Turkey. Significantly the earthquake precursors not within the earth but can be witnessed at the earth atmosphere by manifesting weather anomalies. Apart from the expectation of the best laboratory level of accuracy, its significant result narrowly confined to identify and detect the valid and reliable scientific precursor for any impending individual earthquake for the entire regions of the world. It is quite possible to identify the epicenter of the any huge earthquake tragedies waiting to happen, including its magnitude based on the location and severity of the regional weather changes in just two weeks of time. The method- ology discussed here enhances the feasible solution for predicting the quakes reliably and scientifically. There is currently no reliable way to predict the days or months when an earthquake will occur in any specific location. Each and every form of regional weather changes is followed by respective regional earthquakes in a repeatable manner and the happenings of earthquakes in a given region have a recurrent pattern. The onset of any regional weather changes set a time scale of advancing the regional earthquakes in just 10 to 15 days. Earthquake is a short term process-only few weeks to few months and also happens quite in an orderly pattern.

\section{Rainfall Event Is the Best Earthquake Precursor but Failed to Identified and Detected by Scientists}

Event of rainfall is the one and only the best earthquake precursor. The term "precursor" means two different 
things, in a restricted usage, implies that some anomalous phenomenon that always occurs before an earthquake in a consistent manner [1]. Weather anomalies are known as the significant reliable unambiguous precursor to predict any individual earthquake with the location, magnitude and time (period). Both the rainfall event and the subsequent earthquake events occur in the same general repeatable patterns, because, they are all governed by, same set of physical laws.

Typically there is a very strong direct relationship between the severity of the weather event and the subsequent magnitude of a respective earthquake. All weather anomalies may not followed by earthquakes but $100 \%$ earthquakes are always happening after weather anomaly and more specifically the rainfall events.

\section{List of Unsuccessful Precursors}

Scientists have had more success predicting aftershocks, additional quakes following an initial earthquake but they have been far less successful, however, in finding ways to predict when earthquakes will occur. On the basis of foreshocks, Chinese scientists in 1975 predicted that an earthquake would occur near Haicheng in northern China. Officials' evacuated people from buildings in the area, and just hours later an earthquake struck. Despite that dramatic success, however, seismologists have since come to the conclusion that foreshocks are not a reliable way to predict earthquakes. Many large earthquakes strike with no foreshocks or other warning, and small tremors often occur that are not followed by an earthquake. Global efforts to predict earthquakes were started about a century ago and peaked during 1970s. The first scientifically well documented earthquake prediction was made on the basis of temporal and spatial variation of ts/tp relation in Blue mountain lake, New York on the 3rd August, 1973 There are more than 35 lists of precursory activities includes; radon and Helium emanation; electromagnetic emissions; water level and temperature changes; ground uplift and tilt; changes in ionospheric parameters and so on. But none have been shown to be successful beyond what might be expected by chance.

\section{Happenings of Weather Anomalies}

Although the tropical disturbances exist all the time in each year in different Ocean basins, but only a few of them may develop into tropical cyclones. Weather is all around us and the entire atmosphere sits on the Earth's surface, held in place. Temperature also varies from place to place due to unequal cooling and heating. All form of weather changes are temperature related events in which, water plays a major role in weather. The weather is simply the state of the atmosphere; the gaseous layer that subject to influence from a host of terrestrial and extra- terrestrial forces. There are several extreme forms of weather anomalies like the formation and strengthening of powerful tropical cyclone; days of heavy rain, massive flooding and mudslides; melting snow, heavy snowfall, fog and intense cold wave; high winds and thick plume of dust storm; blighting extreme heat waves and forest fire and massive waves hit the shores.

\section{Happenings of Seismic Events}

It is estimated that around 500,000 earthquakes occur each year, detectable with current instrumentation. About 100,000 of these can be felt. Minor earthquakes occur nearly constantly around the world in places like California and Alaska in the US, as well as in Mexico, Guatemala, Chile, Peru, Indonesia, Iran, Pakistan, the Azores in Portugal, Turkey, New Zealand, Greece, Italy, and Japan, but earthquakes can occur almost anywhere, including New York City, London, and Australia. At the Earth's surface, earthquakes manifest themselves by shaking and sometimes displacement of the ground. When the epicenter of a large earthquake is located offshore, the seabed may be displaced sufficiently to cause a tsunami. Earthquakes can also trigger landslides, and occasionally volcanic activity. Formation of a cyclone process is a "complicated process" and the formation of an earthquake process is a "complex process". The preparatory phase an earthquake, manifest weather anomalies in the atmosphere and the earthquake events, manifest themselves by shaking the ground.

\section{Flawed Understanding of Cyclone Forming}

The formation of tropical cyclone is the topic of extensive ongoing research and because of the flawed understanding of the cyclone formation, the seasonal predictions were often marred by significant errors. With the precise nature of the interaction between the atmosphere and the Ocean is not fully understood, what produces a hurricane or a typhoon? Despite years of effort by many meteorologists, the question has not yet been completely answered. A simple buoyant convective hypothesis will not adequately explain the observed fact. It is scientifically true that the incoming solar radiation is the same on the same date irrespective of the year, but the actual conditions of the surface of the tropical Oceans are by no means the same on the same date of each year. Also, the frequency and intensity of hurricanes varies significantly from year to year, and scientists haven't yet figured out all the reasons for the variability. Globally, about 80 tropical cyclones occur annually. The most active area is the western Pacific Ocean, which contains a wide expanse of warm ocean water. To form a tropical cyclone in most situations, water temperatures of at least $26.5^{\circ} \mathrm{C}$ 
$\left[80^{\circ} \mathrm{F}\right]$ or greater are needed down to depth of at least 50 m (150 feet); water of this temperature cause the overlying atmosphere to be unstable enough to sustain convection and thunderstorms Even though all essential factors satisfied, the cyclone formations are confined to the Island concentrated Ocean basins alone and not everywhere in the western Pacific Ocean and the Island free South Atlantic basins or over any major rivers like Nile, Amazon and lakes like Baikal. So there seems to be no scientific relationship exists between the cyclone formation with the solar energy as prime source and the position of the earth with respect to the Sun. Month May (nearest to the Sun) is the least active month, while September (farthest to the Sun) is the most active month. Cyclones could be formed without the solar energy! Further, the thermal energy factor responsible for cyclone intensification is not in the earth atmosphere but the frictional heat originating under the Ocean bed. This is the reason why the problem of tropical-cyclone intensification continues to challenge both weather forecasters and researchers. For instance, the regions with group of islands in the Oceans are warmer, that indicates the constant seismic activities at work than at the Island free regions Also, the regional geological coordinates for both the tropical Cyclones and the resulting regional quakes are very closely matched. It is from the observations that any form of atrocious weather changes happened in any region, that strongly illustrates the powerful seismic forces at work underground and the process for an earthquake is over in that specific region.

\section{Land Surface Temperature}

In 1980s Russian scientist found some short lived thermal anomalies from satellite image before an earthquake in central Asia .Since then many scientist begun to study this thermal anomaly with satellite data in china, Japan, India, Iran and Algerian earthquakes [2,3]. Although most of the precursors have an important role in the earthquake prediction process, the thermal anomaly precursor is one of the precursors which have gained more attention and support from the scientific community across the world (Panda et al. 2007). Thermal anomaly is an unusual increase in Land Surface Temperature (LST) that occurs around 1 - 24 days prior to an earthquake with increases in temperature of the order of $3^{\circ} \mathrm{C}-12^{\circ} \mathrm{C}$ or more and disappears few days after the event. The proposed method for anomaly detection was also applied on regions irrelevant to earthquakes for which no anomaly was detected, indicating that the anomalous behaviours can be related to impending earthquakes.

Though, there may be various physical explanations for thermal anomalies appearing before an impending earthquake, frictional heat will be most appropriate. The tremendous amount of frictional heat energy generated during the preparatory phase of an earthquake could only responsible for the Land Surface Temperature (LST) anomalies. Further, it has been observed that the thermal anomaly is ground related phenomena, not an atmospheric one [4].

\section{Scientific Reasons That Rainfall Connects Earthquakes}

During the preparatory phase of an earthquake, two blocks of the Earth's crust slide past one another generating massive amounts of frictional heat. In fact, Kanamori \& Brodsky (2001) describe earthquakes as thermal events more than seismic events because most of the energy release during an earthquake goes into heat rather than seismic waves. The actual temperature rise depends on the thickness of the fault zone, which is not known, but for a zone whose thickness is only few centimetres, the temperature could have risen to above $5000^{\circ} \mathrm{C}$. However, seismologists have never directly observed ruptures occurring in Earth's interior. Instead, they rely on the information gleaned from the few available types of data, the most important of which is the record of seismic waves $[5,6]$. This tremendous quantity of heat energy is continuously fed into the atmosphere, setting into motion and creating weather. This massive amounts of frictional heat generated within the earth, reaches on to the Ocean surface by means of convection, a large amounts of steamy water rise off the ocean, forming an area of low pressure (tropical depression). The tropical cyclone draws energy from its thermal reservoir-the warm water at the surface of the Ocean. In this way, the frictional heat responsible for the direct and primary cause for all form of weather changes includes the formation and strengthening of powerful tropical cyclone; cluster of tornadoes; days of heavy rain, massive flooding and mudslides; melting snow, heavy snowfall, fog and intense cold wave; high winds and thick plume of dust storm; record breaking heat waves and forest fire; massive waves hit the shores.

\section{Minimum Two Weeks Period for the Clamping Stress Overcome by the Shear Stress}

The instigating factor in earthquake triggering is pressureor stress, transmitted through rock to a fault. If the clamping stress, oriented perpendicular to the fault surface and which acts to hold the fault in place, is overcome by the shear stress, which forces the two sides of a fault to slide parallel against each other, then the fault will rupture. This would be the reason for the minimum two weeks of time delay, between the happenings of the 
rainfall event and the subsequent earthquake event.

\section{Correlation between Rainfall and Earthquakes}

A scientist, Jerome Mamias, from scrip institution of Oceanography publish a paper In 1989 suggesting that earthquake do occur more often in hot weather.

Since, the solid earth surface is in direct contact with atmosphere and oceans and its evolving. The subsurface seismic shaking effects, affects the everyday surface atmospheric weather condition. Because the preparatory phase of the earthquakes itself generates observable anomalies in the atmospheric weather conditions. The overall atmospheric disturbances are seems to be controlled by the seismic events, without which there would be practically no atmospheric weather anomalies. The Ocean water (above $4^{\circ} \mathrm{C}$ ) is less dense as its temperature increases. This allows surface cold water to sink to the bottom. Basic Physics suggest that a warmer atmosphere can hold more water vapour, for example and should therefore develop more storms [7]. Besides the reports of thermal anomaly related seismic activity, data gaps caused by cloud cover [8], indicates that there was cloud formation during the period of thermal anomalies as reported: "A difference in the time of appearance of the thermal IR anomalies has been observed in day time and night time data at the Bam, Bhuj and other studied earthquakes. This is probably due to the typical meteorological phenomena or the appearance of clouds [9]. Understanding the law of heat transfer, that heat moves to the cooler region until both reach equilibrium.”

\section{Unification of Weather Anomalies and Earthquakes}

So far, both the weather and seismic events are observed as continuous and unpredictable and also viewed as not interconnected with one another. The failure of earthquake prediction is not only because of negative observa- tion of precursor phenomena but also due to the failure in connecting the seismic events with the atmospheric events. Weather precursors to earthquakes are the one-to-one correlation. Rainfall is always associated and accompanied with any one of the weather conditions like heat waves, wildfire, strong winds and snow fall. Among the list of weather precursors, the location of rainfall event alone, enough to forecast the epicenter of any forthcoming individual earthquake precisely. Because, during the preparatory phase of a specific seismic regional events are always affect the respective atmospheric weather of a specific regions (Tables 1-3 summarized for the entire regions of South Pacific, Iran and Italy respectively). The happenings of earthquake after weather anomalies are like thunder after lightning. Without identifying the correct earthquake precursory signal that consistently occurs before earthquakes, it would be impossible to predict any individual earthquake of small or big one. It is impossible to predict when and where the next cyclone will form, but based on the location of the cyclone formation it quite possible to say when and where the next earthquake will happen.

\section{Observations}

Irrespective of ocean depth (regions like Philippines and Fiji) earthquake events are happening after the rainfall events in a consisting manner in two weeks of time is remarkable to mention. Year after year, many faults in different regions of the world tend to produce repeated earthquakes but varying magnitude, depth, rupture length and rupture mechanism. For the past five years thousands of events are warned, observed, tabulated and analyzed in a rigorous manner for the entire regions of the world (see Tables 1-5).

\section{Methodology}

It is quite possible to make the prediction of any individual earthquake to the maximum possible confidence level.

Table 1. Regions of earthquakes occur after rainfall in South Pacific regions.

\begin{tabular}{|c|c|c|}
\hline South Pacific Region & Regional Rainfall & Regional Earthquakes \\
\hline 1) PNG & $07^{\circ} \mathrm{N}-10^{\circ} \mathrm{S} 141-158^{\circ} \mathrm{E}$ & $02-06^{\circ} \mathrm{S} 141-154^{\circ} \mathrm{E}$ \\
\hline 2) Solomon Islands & $08-10^{\circ} \mathrm{S} 156-165^{\circ} \mathrm{E}$ (Australia: 12 - $27^{\circ} \mathrm{S} 142-153^{\circ} \mathrm{E}$ ) & $07-12^{\circ} \mathrm{S} 155-166 \mathrm{E}$ \\
\hline 3) New Caledonia \& Vanuatu & $13-22^{\circ} \mathrm{S} 163-169^{\circ} \mathrm{E}$ & $14-22^{\circ} \mathrm{S} 166-173^{\circ} \mathrm{E}$ \\
\hline 4) Fiji \& Tonga & $12-21^{\circ} \mathrm{S} 171-179^{\circ} \mathrm{E}$ (Australia: $23-26^{\circ} \mathrm{S} 144,150-153^{\circ} \mathrm{E}$ ) & $18-24^{\circ} \mathrm{S} 172-179^{\circ} \mathrm{W}$ \\
\hline 5) Kermadec Islands & $25-38^{\circ} \mathrm{S} 144-153 \& 172-178^{\circ} \mathrm{E} \& 178^{\circ} \mathrm{W}$ & $24-39^{\circ} \mathrm{S} 173-179^{\circ} \mathrm{E}$ \\
\hline 6) South Islands (New Zealand) & $39-45^{\circ} \mathrm{S} 169-174^{\circ} \mathrm{E}$ & $40,43-44^{\circ} \mathrm{S} 168.172,175-176^{\circ} \mathrm{E}$ \\
\hline 7) Macquarie Island & $36-37,40-41^{\circ} \mathrm{S} 145-148,166^{\circ} \mathrm{E}$ & $\begin{array}{c}36,38,54,57,59,61,63,65^{\circ} \mathrm{S} 143,146,148, \\
153,164,170,177^{\circ} \mathrm{E}\end{array}$ \\
\hline
\end{tabular}


Table 2. Regions of earthquakes occur after rainfall in Iran.

\begin{tabular}{lcc}
\hline \multicolumn{1}{c}{ Iran Region } & Regional Rainfall & Regional Earthquakes \\
\hline 1) Eastern Iran & $36-37^{\circ} \mathrm{N} 54-55^{\circ} \mathrm{E}$ & $32-33^{\circ} \mathrm{N}$, \\
& $58-59.382^{\circ} \mathrm{E}$ \\
2) Western Iran & $\begin{array}{c}30-37^{\circ} \mathrm{N} 44,48-51, \\
54-55^{\circ} \mathrm{E}\end{array}$ & $31-34 \mathrm{~N} 48-50 \mathrm{E}$ \\
& \\
3) Southern Iran & $\begin{array}{c}50-30^{\circ} \mathrm{N}, 42,44, \\
50-59^{\circ} \mathrm{E}\end{array}$ & $26-29^{\circ} \mathrm{N}, 51-59^{\circ} \mathrm{E}$ \\
& $33,36-41^{\circ} \mathrm{N}, 41$, & $35-40^{\circ} \mathrm{N}, 46,51-53$, \\
4) Northwestern Iran & $44-56^{\circ} \mathrm{E}$ & $58-59^{\circ} \mathrm{E}$ \\
\hline
\end{tabular}

Table 3. Regions of earthquakes occur after rainfall in Italy.

\begin{tabular}{lcc}
\hline \multicolumn{1}{c}{ Italy Region } & Regional Rainfall & Regional Earthquakes \\
\hline $\begin{array}{l}\text { 1) Northern Italy } \\
\text { (Jan-June-2012) }\end{array}$ & $40-49^{\circ} \mathrm{N} 01-18^{\circ} \mathrm{E}$ & $41,44-46^{\circ} \mathrm{N} 07,09-12^{\circ} \mathrm{E}$ \\
$\begin{array}{l}\text { 2) Southern Italy } \\
\text { (Feb-Oct-2012) }\end{array}$ & $36-44^{\circ} \mathrm{N} 11-15^{\circ} \mathrm{E}$ & $38-41^{\circ} \mathrm{N} 13-16^{\circ} \mathrm{E}$ \\
\hline
\end{tabular}

Rainfall events are earthquake precursors as a valid only prediction method for every individual earthquake for the entire regions of the world. I have verified more than 1000 of events in the past five years and also continuously sending earthquake warnings based on the weather precursor to more than 2500 quakes events in the same duration to a list of experts to the concerned region. I warned, observed and recorded the earthquake of magnitude M4+ against the rainfall $50 \mathrm{~mm}$ above for the entire regions of the world. By applying this prediction method, without wasting away any precious time, scientists can ensure and prevent any horrific loss of life by any potential earthquake and tsunami!

Only at the instant of noticing the location and amount of rainfall on a weather map using the web site $[10,11]$ and with the help of the observation table given below, except precise time, it is quite possible to identify the epicentre of the location and magnitude of any forthcoming earthquake(s) in E Turkey.

With the study of interdisciplinary experts based on these findings, the accuracy could be promoted certainly. This promising earthquake prediction method is quite easy, quick and also low cost.

\section{Results}

\subsection{Location}

The geological coordinates of the origin of the weather changes (geological process within the earth) are vitally very important (because a storm may move thousands of kilometers away from its origin) for fixing the geological coordinates for any forthcoming earthquakes. Sometimes the regional weather changes over a same region have been affected by the different geological process of dif- ferent adjacent regions.

\subsection{Magnitude}

The magnitudes of a resulting individual earthquake depend on the severity of the weather changes and also depends local site geology and other factors. Up to Magnitude 5 for any individual event of rain fall 50 to 100 $\mathrm{mm}$. M5-6 for a wide spread rainfall (say 50 to $100 \mathrm{~mm}$ and above).

M6-7 for a very wide spread continuous heavy rain (say 50 to $100 \mathrm{~mm}$ and above), plus blighting extreme heat waves and forest fire.

M7-8+ any record breaking weather changes (heaviest snowfall) always followed by huge destructive quakes (Table 5: precursor to the March 11, 2011 Japan tsunami).

\subsection{Time}

Normally, the time interval between the regional weather changes and the resulting respective individual earthquake(s) are usually around 10 to 15 days. However, for a heaviest snow fall, the resulting earthquake takes nearly 2 - 3 months of time. Only at the laboratory level, it is quite possible to predict the precise time of any forthcoming earthquake. Like seasonal weather changes, earthquakes are also having a cyclic pattern to occur year after year in the same region except its magnitude, which will vary in accordance with the extremity of the regional weather changes.

\section{Conclusions}

In my continuous efforts, I got the results conformed to reality. Though there are several other methods and models used to predicting both the monsoon and earthquakes, but all are turned significantly unsuccessful.

It is quite impossible to say when and where the next cyclone will form and at what intensity, but based on the location of low depression formation, it is quite possible to say when and where will the next earthquake will occur and also its magnitude based on the severity of the weather event.

Reliably there is some physical connection between the weather anomalies and the subsequent earthquake event. It can be observed that the weather changes are not having any surface origin but often very closely related to geological process within the earth, the preparatory phase of an earthquakes and both responding the same dynamic earth forces. It has been observed that the seasonal weather changes are due to the orbital motion of the earth and, in the same way the constant trigger of large-scale effects of plate tectonics could be with the same effects of orbital motion of the earth. Without in- 
Table 4. Regions of earthquakes occur after rainfall in E Turkey.

\begin{tabular}{|c|c|c|c|}
\hline \multicolumn{2}{|c|}{ RAINFALL (Syria, Israel, Iraq, Jordan) } & \multicolumn{2}{|c|}{ EARTHQUAKES (Eastern Turkey/Turkey-Syria-Iraq border region) } \\
\hline Date & Location \& Qty. > 50 mm & Date/Mag. > 4 & Lat./Long \\
\hline Jan 1 \& 06, 2012 & $\left(32,34-35^{\circ} \mathrm{N} 34-36^{\circ} \mathrm{E}\right)(50-680 \mathrm{~mm})$ & $\begin{array}{l}\text { a) Jan } 06,2012 / \mathrm{M} 4.6 \\
\text { b) Jan } 06,2012 / \mathrm{M} 4.3\end{array}$ & $\begin{array}{l}\text { a) } 38.829^{\circ} \mathrm{N}, 43.788^{\circ} \mathrm{E} \\
\text { b) } 37.772^{\circ} \mathrm{N}, 42.618^{\circ} \mathrm{E}\end{array}$ \\
\hline Jan 6-9, 2012 & $\left(35-36^{\circ} \mathrm{E} 32 \& 35^{\circ} \mathrm{E}\right)(51-109 \mathrm{~mm})$ & $\begin{array}{l}\text { a) Jan } 10,2012 / \mathrm{M} 4.0(\mathrm{M} 4.1 \text { on Jan } 11) \\
\text { b) Jan 20, 2012/M4.7 } \\
\text { c) Jan 22, 2012/M4.2 }\end{array}$ & $\begin{array}{l}\text { a) } 38.805^{\circ} \mathrm{N}, 43.543^{\circ} \mathrm{E} \\
\text { b) } 38.657^{\circ} \mathrm{N}, 43.476^{\circ} \mathrm{E} \\
\text { c) } 38.678^{\circ} \mathrm{N}, 44.166^{\circ} \mathrm{E}\end{array}$ \\
\hline Jan 11-17, 2012 & $\begin{array}{l}(32 \& 36-387 N 29-30,32,35 \& 40 E) \\
(50-62 \mathrm{~mm})\end{array}$ & Jan 29, 2012/M 4.5 & $38.722^{\circ} \mathrm{N}, 43.614^{\circ} \mathrm{E}$ \\
\hline Jan 22, 2012 & $\begin{array}{l}\left(32 \& 35-36^{\circ} \mathrm{N} 30 \& 32,35^{\circ} \mathrm{E}\right) \\
(54-72 \mathrm{~mm})\end{array}$ & $\begin{array}{l}\text { a) Feb 16, 2012/M4.6 } \\
\text { b) Feb 17, 2012/M4.6 }\end{array}$ & $\begin{array}{l}\text { a) Central Turkey: } 38.651^{\circ} \mathrm{N}, 37.413^{\circ} \mathrm{E} \\
\text { b) } 38.590^{\circ} \mathrm{N}, 43.221^{\circ} \mathrm{E}\end{array}$ \\
\hline $\begin{array}{l}\text { a) Feb 7, } 2012 \\
\text { b) Feb. 9, } 2012\end{array}$ & $\begin{array}{l}\text { a) }\left(3428^{\circ} \mathrm{N} 4157^{\circ} \mathrm{E} 606 \mathrm{~mm}\right) /\left(36^{\circ} \mathrm{N} 30^{\circ} \mathrm{E}\right. \\
(63-69 \mathrm{~mm}) \\
\text { b) }\left(36 \& 41^{\circ} \mathrm{N} 30,36 \& 41^{\circ} \mathrm{E}\right) \\
(58-69 \mathrm{~mm})\end{array}$ & $\begin{array}{l}\text { a) Feb 20, 2012/M } 4.1 \\
\text { b) Feb 24/29, } 2012 \text { M 4.5/4.3 }\end{array}$ & $\begin{array}{l}\text { a) } 38.429^{\circ} \mathrm{N}, 43.376^{\circ} \mathrm{E} \\
\text { b) } 38.640^{\circ} \mathrm{N}, 43.621^{\circ} \mathrm{E}\end{array}$ \\
\hline Feb. 28, 2012 & $\begin{array}{l}\left(3702^{\circ} \mathrm{N} 2726^{\circ} \mathrm{E} 66 \mathrm{~mm}\right) / \text { Egypt } \\
\left(3117^{\circ} \mathrm{N} 3214^{\circ} \mathrm{E} 890 \mathrm{~mm}\right)\end{array}$ & $\begin{array}{l}\text { a) March 24, 2012/M4.4 } \\
\text { b) March 26, 2012/M5.2 } \\
\text { c) March 31, 2012/M4.1 (M4.5 on Apr.4) } \\
\text { d) April 04, 2012/M4.3 } \\
\text { e) April 04, 2012/M4.2 } \\
\text { f) April 18, 2012/M4.5 } \\
\text { g) April 13, 2012/M4.2 } \\
\text { h) April 28, 2012/M4.7 }\end{array}$ & $\begin{array}{l}\text { a) } 38.917^{\circ} \mathrm{N}, 43.532^{\circ} \mathrm{E} \\
\text { b) } 39.137^{\circ} \mathrm{N}, 42.316^{\circ} \mathrm{E} \\
\text { c) } 39.078^{\circ} \mathrm{N}, 43.776^{\circ} \mathrm{E} \\
\text { d) } 39.234^{\circ} \mathrm{N}, 41.072^{\circ} \mathrm{E} \\
\text { e) Turkey-Syria border: } 36.963^{\circ} \mathrm{N} \text {, } \\
36.970^{\circ} \mathrm{E} \\
\text { f) } 38.966^{\circ} \mathrm{N}, 43.610^{\circ} \mathrm{E} \\
\text { g) } 38.406^{\circ} \mathrm{N}, 43.449^{\circ} \mathrm{E} \\
\text { h) } 38.395^{\circ} \mathrm{N}, 40.789^{\circ} \mathrm{E}\end{array}$ \\
\hline March 18, 2012 & $\left(37^{\circ} \mathrm{N} 49^{\circ} \mathrm{E}\right)(53-64 \mathrm{~mm})$ & March 24, 2012/M4.9 (M4.5) & Iran-Iraq border: $32.606^{\circ} \mathrm{N}, 47.032^{\circ} \mathrm{E}$ \\
\hline May 25, 2012 & $\left(3949^{\circ} \mathrm{N} 3448^{\circ} \mathrm{E} 57 \mathrm{~mm}\right)$ & May 25, 2012/M4.3 & $38.226^{\circ} \mathrm{N}, 38.621^{\circ} \mathrm{E}$ \\
\hline June 23, 2012 & $\left(3449^{\circ} \mathrm{N} 3608^{\circ} \mathrm{E} 63.9 \mathrm{~mm}\right)$ & June 24, 2012/M 4.9 & $38.741^{\circ} \mathrm{N}, 43.615^{\circ} \mathrm{E}$ \\
\hline $\begin{array}{l}\text { a) July 08, } 2012 \\
\text { b) July 10, } 2012\end{array}$ & $\begin{array}{l}\text { a) }\left(4033^{\circ} \mathrm{N} 4305^{\circ} \mathrm{E} 109 \mathrm{~mm}\right) \\
\text { b) }\left(4124^{\circ} \mathrm{N} 4126^{\circ} \mathrm{E} 52 \mathrm{~mm}\right)\end{array}$ & $\begin{array}{l}\text { a) July } 20,2012 / M 4.3 \\
\text { b) July } 24,2012 / M 4.5 \\
\text { c) July } 31,2012 / M 4.1\end{array}$ & $\begin{array}{l}\text { a) Georgia: } 42.500^{\circ} \mathrm{N}, 44.103^{\circ} \mathrm{E} \\
\text { b) } 38.654^{\circ} \mathrm{N}, 43.403^{\circ} \mathrm{E} \\
\text { c) } 38.783^{\circ} \mathrm{N}, 43.158^{\circ} \mathrm{E}\end{array}$ \\
\hline July 30, 2012 & Georgia $\left(4202^{\circ} \mathrm{N} 4329^{\circ} \mathrm{E} 616 \mathrm{~mm}\right)$ & Aug 05, 2012/M4.9 & $37.471^{\circ} \mathrm{N}, 42.896^{\circ} \mathrm{E}$ \\
\hline Aug. 07-08, 2012 & $\left(41-42^{\circ} \mathrm{N} 35-36^{\circ} \mathrm{E}\right)(61-64 \mathrm{~mm})$ & Aug. 19, 2012/M4.3 & $39.924^{\circ} \mathrm{N}, 43.814^{\circ} \mathrm{E}$ \\
\hline Sep. 23, 2012 & $\left(4124^{\circ} \mathrm{N} 4126^{\circ} \mathrm{E} 170 \mathrm{~mm}\right)$ & $\begin{array}{l}\text { a) Sep.23, 2012/M4.5 } \\
\text { b) Oct } 01,2012 / \mathrm{M} 4.6\end{array}$ & $\begin{array}{l}\text { a) } 38.492^{\circ} \mathrm{N}, 43.128^{\circ} \mathrm{E} \text {. } \\
\text { b) } 38.545^{\circ} \mathrm{N}, 55.603^{\circ} \mathrm{E}\end{array}$ \\
\hline Nov. 11-12, 2012 & $\left(37-38^{\circ} \mathrm{N} 40^{\circ} \mathrm{E}\right)(51-55 \mathrm{~mm})$ & Nov. 20, 2012/M4.3 & $39.446^{\circ} \mathrm{N}, 39.855^{\circ} \mathrm{E}$ \\
\hline
\end{tabular}

Table 5. Historic heaviest snowfall and snow storm precursor to the March 11, 2011 Tsunami.

\begin{tabular}{|c|c|c|c|}
\hline \multicolumn{2}{|r|}{ HEAVIEST SNOWFALL } & \multicolumn{2}{|c|}{ EARTHQUAKES } \\
\hline Date & Location and Area & Date/Mag. > 4 & Lat./Long \\
\hline Jan. 01, 2011 & $\begin{array}{l}\text { TOTTORI, Japan, Jan. } 1 \text { (UPI)_-Snowstorm blanketed parts } \\
\text { of Japan with up to } 43 \text { inches whipped by winds up to } 63 \\
\text { mph, the most since measurements were started in } 1940 \text {. }\end{array}$ & $\begin{array}{l}\text { March 09-10, 2011/M7.2 } \\
\text { (M5.6, 5.2, 5.0, 4.8, 6.1, 6.0). }\end{array}$ & a) $38.510^{\circ} \mathrm{N}, 142.792^{\circ} \mathrm{E}$. \\
\hline Feb. 14, 2011 & $\begin{array}{l}\text { Heaviest snowfall Feb.14. The heaviest snowfall in more } \\
\text { than a century on South Korea's east coast. recorded } 80 \mathrm{~cm} \\
\text { ( } 2.6 \text { feet) since records began there back in } 1911 .\end{array}$ & $\begin{array}{l}\text { March 11, 2011/M8.9 Near East coast of } \\
\text { Honshu, Japan, Friday, (East of Sendai, } \\
\text { Honshu, Japan), Depth: } 24.4 \text { km.. }\end{array}$ & b) $8.322^{\circ} \mathrm{N}, 142.369^{\circ} \mathrm{E}$ \\
\hline
\end{tabular}


cluding the weather anomalies prediction of earthquakes are impossible and without considering effects of crustal movements and its effect on atmosphere, it would be impossible to predict monsoon successfully.

\section{Acknowledgements}

This paper would not have been possible without the data source available from the websites USGS and WMO.

I am very particularly grateful to Dr. Michael L Blanpied, Associate Coordinator, USGS Earthquake Hazards Program for his all time pleasing and suggesting expert level of very valuable scientific guidance through his numerous correspondence. Then I would like to express my very great appreciation to Dr. Jeremy Zechar, scientist, CSEP, USA, a man of helping tendency, for his sincere efforts to turn my hypothesis into testable statements.

I am very much thankful to T. Tamilselven, Managing Director, Super Quality Services for his magnanimous financial assistance and permission to publish this manuscript.

My special thank goes to Prof. Dr. K. V. Gopalakrishnan, (Deceased) IIT, Chennai, India; Dr. P. Srinivasulu, Deputy Director (Retd), SERC, CSIR, Chennai, India and Mr. S. Nagarajan, Salem, Tamilnadu, India, serves as a great source of inspiration and support for more than 25 years. Finally my heartfelt thanks to the SCIRP grant office, unknown reviwers of this manuscript and my family members and friends for their every valuable help and assistance.

\section{REFERENCES}

[1] H. Kanamori, "Earthquake Prediction: An Overview," Internationl Handbook of Earthquake and Engineering
Seismology, Vol. 616, 2003, pp. 1205-1216.

[2] A. K. Saraf and S. Choudhury, "Satellite Detects Surface Thermal Anomalies Associated with the Algerian Earthquakes of May 2003,” International Journal of Remote Sensing, Vol. 26, No. 13, 2005, pp. 2705-2713. doi:10.1080/01431160310001642359

[3] A. K. Saraf and S. Choudhury, "SSM/I Applications in Studies of Thermal Anomalies Associated with Earthquakes,” International Journal Geoinformatics, Vol. 2, No. 3, 2005, pp. 197-207.

[4] A. K. Saraf and S. Choudhury, "NOAA-AVHRR Detects Thermal Anomaly Associated with 26 January, 2001 Bhuj Earthquake, Gujarat, India,” International Journal of Remote Sensing, Vol. 26, No. 6, 2005, pp. 1065-1073. doi:10.1080/01431160310001642368

[5] M. S. Vassiliou and H. Kanamori, "The Energy Release in Earthquakes," Bulletin of the Seismological Society of America, Vol. 72, No. 2, 1982, pp. 371-387.

[6] H. Kanamori, "The Energy Release in Great Earthquakes,” Journal of Geophysical Research, Vol. 82, No. 20, 1977, pp. 2981-2876. doi:10.1029/JB082i020p02981

[7] Q. Schiermeier, "Climate and Weather: Extreme Measures,” Nature, Vol. 477, 2011, pp. 148-149. doi:10.1038/477148a

[8] M. Blackett, M. J. Wooster and B. D. Malamud, "Exploring Land Surface Temperature Earthquake Precursors: A Focus on the Gujarat (India) Earthquake of 2001," Geophysical Research Letters, Vol. 38, 2011, Article ID: L15303. doi:10.1029/2011GL048282

[9] Detecting Earthquake Precursor, "A Thermal Remote Sensing Approach Arun K. Saraf,” Map India, 2008.

[10] http://severe.worldweather.wmo.int/rain/b3/index.html

[11] http://earthquake.usgs.gov/ 